\title{
Correlation between the Perception of Personal Dental Appearance and the Residual Treatment Need amongst Underserved Indian Adolescents
}

\section{Aditi Verma ${ }^{*}$, Archana $\mathbf{K}^{2}$ and Pramila $\mathbf{M}^{3}$}

${ }^{1}$ Department of Public Health Dentistry, Jamia Millia Islamia, India

${ }^{2}$ Department of Public Health Dentistry, Oxford Dental College \& Hospital, India

${ }^{3}$ Department of Public Health Dentistry, MR Ambedkar Dental College \& Hospital, India

*Corresponding author: Aditi Verma, Department of Public Health Dentistry, Faculty

\section{Research Article}

Volume 4 Issue 2

Received Date: April 30, 2019

Published Date: May 17, 2019

DOI: 10.23880 /oajds-16000229 of Dentistry, Jamia Millia Islamia, New-Delhi, India, Tel: +91-7838198227; Email: ver.aditi@gmail.com

\section{Abstract}

Background: Measurement of malocclusion as a public health problem is extremely difficult since individual perceptions of malocclusion differs widely. Hence, planning orthodontic treatment within a public system requires information regarding aesthetic perception, their need and demand for orthodontic treatment.

Materials and Methods: The study assessed perception of dental attractiveness along with the need and demand for orthodontic treatment amongst Indian school children belonging to low socio-economic status. Study was conducted in North zone of Bangalore city; India involving 1010 children (460 boys and 550 girls) aged 12-15 years 'government high schools. Pre-structured questionnaire in English language was administered including demographic characteristics, awareness of children's own occlusions along with the visual perceptions of malocclusion comprising of two questions related to 10 standard intra-oral IOTN (Index of Orthodontic and Treatment Need) frontal photographs on which the subjects had to give an opinion about attractiveness. Clinical examination was also done using DAI (Dental Aesthetic Index) to assess severity of malocclusion along with its corresponding treatment need for the subjects.

Results: Statistically significant difference was obtained between the subjective perception of occlusion amongst boys and girls. A negative although insignificant correlation was also observed between dental aesthetic index and the subjective perception of malocclusion for children belonging to low socio-economic status.

Conclusion: Significant proportions of the children belonging to low socio-economic status were unaware and viewed their dental appearance as pleasant. Thus, there is a residual unmet need for orthodontic treatment among a majority of Indian children.

Keywords: Epidemiology; Malocclusion; Perception; Orthodontics; Underserved School children 


\section{Open Access Journal of Dental Sciences}

\section{Introduction}

Well-aligned teeth and a pleasing smile reflect positive status at all social levels and irregularity or protruding teeth reflect negative status [1]. A malocclusion is considered as a deviation from the ideal occlusion, which may range from mild to considerable from the acceptable norm [2].

Increased concern over dental appearance has been observed during childhood and adolescence to early adulthood. The decision to start orthodontic treatment is primarily influenced by such concerns and psychological well-being [3]. Dentist predict that the psychological component of malocclusion will continue to be one of the strongest motivator for the orthodontic treatment and it is very difficult to estimate the extent to which malposed teeth or dento-facial mal-relation constitute a psychological hazard [4]. Thus, the measurement of malocclusion as a public health problem is extremely difficult since individual perceptions of what constitutes a malocclusion problem differs widely.

The relationship between professionally assessed and self-perceived treatment need is of interest to providers of public health services. Over the years, a variety of indices have been developed to assist professionals and amongst them, Dental Aesthetic Index and Index of Orthodontic Treatment Need are well-known indices for assessment of malocclusion and determination of treatment need.

Use of such indices allows the clinicians to assess the individuals with the greatest need of orthodontic treatment and individuals with little need for treatment taking in the consideration of availability of resources [5]. Thus, planning orthodontic treatment within a public health system requires the information regarding their aesthetic perception along with the need and demand for orthodontic treatment.

Hence, the present study was undertaken to assess the perception of dental attractiveness along with the need and demand for the orthodontic treatment amongst school children specially belonging to low socio-economic status, who are not able to afford the cost of dental treatment and to find the correlation between the demand and need for their orthodontic treatment.

\section{Materials and Methods}

\section{Study Settings and Participants}

The present study was performed among the school children belonging to low socio-economic status (460 boys and 550 girls) aged 12-15 years from government high schools. The Deputy Director of Public Instructions (DDPI) divided the schools in Bangalore, Karnataka, India into three zones: north, south and rural. On basis of the pilot results, 1010 subjects were selected by stratified random sampling from the north zone, which was selected randomly by a lottery method for the purpose of this study. The classes and the children were selected randomly from selected schools for the inclusion in the study. Inclusion criteria included:

a) Schools coming under DDPI - list of high schools

b) Subjects belonging to low socio-economic status [Lower and Upper Lower class as verified using Modified Kuppuswamy's Scale] and

c) Willingness of subjects to participate in the study. The age of the subject's was verified by the school records prior their participation in the study.

The exclusion criteria included:

a) Subjects with previous history of or currently undergoing orthodontic or orthopedic treatment

b) Subjects who have decided about the orthodontic treatment at the time of study

c) Subjects with mental or physical impairments, and with syndromes

d) Subjects with complete primary or mixed dentition.

Permission was obtained from the concerned authorities \{Deputy Directorate of Public Instructions (DDPI), Bangalore $\}$ and the head of the respective schools. Ethical clearance was obtained from Institutional Review Board and informed consent was obtained from the study subjects prior to the commencement of the study. This study was conducted in accordance with the Declaration of Helsinki.

\section{Development and Testing of Instrument}

A structured questionnaire in English language was administered to the children in their classroom on the scheduled days. Suitability of the questionnaire was checked by inviting six experts to provide their comment on the questionnaire. No revision was needed following questionnaire evaluation. The questionnaire was then pilot tested with 110 students (12-15 years) at one of the high schools in Bangalore, India. Based on the problems faced when administering the questionnaire during the pilot study, changes were made and the reliability of the questionnaire was tested using Cronbach's alpha which came out as $\alpha=0.75$ suggesting an acceptable reliability.

The study questionnaire was divided into three sections: The first section asked for the demographic characteristics particularly age, sex, parents' education and employment status. The second section dealt with awareness of children's own occlusions, including seven 


\section{Open Access Journal of Dental Sciences}

questions on their subjective need of treatment, satisfaction with the arrangement and appearance with their teeth and the importance of well-aligned teeth. The questions were scaled and scored with a 3 point Likert's scale. The third section concerned with the respondents' visual perceptions of malocclusion, comprised of two questions related to 10 intra-oral frontal photographs on which the subjects had to give an opinion about attractiveness. The ten standard intraoral frontal photographs represented the aesthetic component (AC) of the Index of Orthodontic Treatment Need (IOTN). Before the data collection, the respective class teachers gave a brief introduction about the investigator (AV) and the investigator (AV) answered all queries regarding the questions.

\section{Clinical Examination}

The same investigator (AV) underwent the training and calibration for using Dental Aesthetic Index (DAI) before conducting the clinical examination. The intraexaminer reliability was assessed using Kappa, came out to be 0.81 indicating an acceptable agreement.

The clinical examination was carried out during daytime under natural light with help of community periodontal index probe (CPI Probe) to assess the severity of malocclusion along with its corresponding treatment need for the subjects using Dental Aesthetic Index (DAI). The measured components of the DAI were multiplied by the regression coefficient (weights), the products and the constant number was added to give the final DAI score. The accepted standards of infection control were maintained and the need for privacy and confidentiality was stressed.

\section{Data Analysis}

Data processing and Analyses were performed using Statistical Package for the Social Sciences Version 18.0 (IBM Corp., Armonk, NY, USA). Pearson's Chi-square test was used to find the significant relationship between the variables of the questionnaire and demographic variables of the study population. Kappa correlation was then used for analysing the degree of agreement between the objective (as determined by the dentists via clinical examination) and subjective (as felt by the subjects) treatment need for the orthodontic treatment.

\section{Results}

All the 1010 subjects responded to the questionnaire and agreed to participate in the clinical examination. A total of $360(35.6 \%)$ of the subjects belonged to age group 12-15 years while $650(64.4 \%)$ to $14-15$ years of age. Male: Female ratio was 46:55 (Mean $=13.83$ years \pm 1.98 ) belonged to lower SES group and was verified by Kuppuswamy's socioeconomic scale.

Graph 1 depicts the overall subjective perception of the subjects based on the questionnaire. Table 1 reveals the gender difference of significance in the opinions about the subjective perception of the occlusion amongst study subjects. In response to the question regarding the satisfaction with smile, $71 \%$ of subjects perceived their smile as pleasant and statistically significant difference $(p<0.05)$ was found amongst the gender for the satisfaction with the appearance of their smile (question 1) (Table 1).

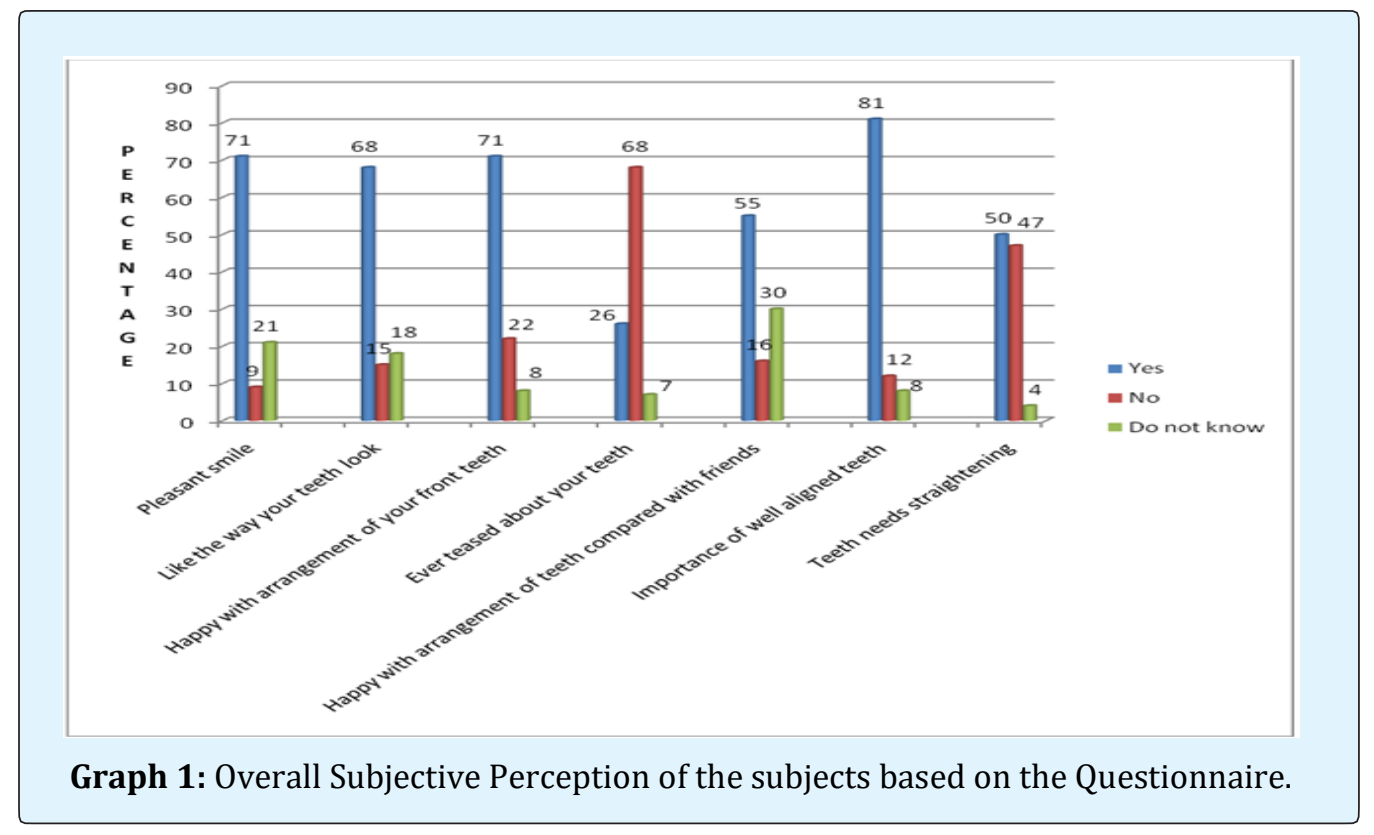

Aditi Verma, et al. Correlation between the Perception of Personal Dental Appearance and the Residual Treatment Need amongst Underserved Indian Adolescents. J Dental Sci 2019, 4(2): 000229. 


\section{Open Access Journal of Dental Sciences}

\begin{tabular}{|c|c|c|c|c|}
\hline Questionnaire & Score & Boys (\%) & Girls (\%) & Total (\%) \\
\hline \multirow{3}{*}{ Q1* } & Yes & 54.3 & 83.6 & 70.3 \\
\hline & No & 17.4 & 1.8 & 8.9 \\
\hline & Do not know & 28.3 & 14.5 & 20.8 \\
\hline \multirow{3}{*}{$\mathrm{Q} 2^{*}$} & Yes & 56.5 & 76.4 & 67.3 \\
\hline & No & 23.9 & 7.3 & 14.9 \\
\hline & Do not know & 19.6 & 16.3 & 17.8 \\
\hline \multirow{3}{*}{ Q3 } & Yes & 71.7 & 69 & 70.3 \\
\hline & No & 15.2 & 27.3 & 21.8 \\
\hline & Do not know & 13.1 & 3.7 & 6.9 \\
\hline \multirow{3}{*}{ Q4 } & Yes & 34.8 & 18.1 & 25.7 \\
\hline & No & 58.7 & 74.5 & 67.3 \\
\hline & Do not know & 6.5 & 7.3 & 6.9 \\
\hline \multirow{3}{*}{ Q5 } & Yes & 65.2 & 45.5 & 54.5 \\
\hline & No & 15.2 & 16.4 & 15.8 \\
\hline & Do not know & 19.6 & 38.1 & 29.7 \\
\hline \multirow{3}{*}{ Q6* } & Yes & 69.6 & 89 & 80.2 \\
\hline & No & 21.7 & 3.6 & 11.9 \\
\hline & Do not know & 8.7 & 7.4 & 7.9 \\
\hline \multirow{3}{*}{ Q7 } & Yes & 60.9 & 40 & 49.5 \\
\hline & No & 37 & 54.5 & 46.5 \\
\hline & Do not know & 2.1 & 5.5 & 4 \\
\hline
\end{tabular}

* Pearson Chi-Square Significant $(\mathrm{P}<0.05)$

Table 1: Sex wise distribution of subjects according to the responses to questionnaire.

Sixty eight subjects liked the way their teeth look like (question 2). $76.4 \%$ of girls liked the way their teeth looked like compared with $56.5 \%$ of boys. This difference in perception amongst boys and girls was found to be statistically significant $(\mathrm{p}<0.05)$ (Table 1$)$.

Approximately, $89 \%$ of the girls considered wellaligned teeth important for their facial appearance in comparison to $69 \%$ of boys (question 6). This difference amongst the opinion of boys and girls was again found to be statistically significant $(\mathrm{p}<0.05)$ (Table 1$)$.

Their visual perception of subject occlusion was also assessed using 10 standard intra-oral occlusion photographs of aesthetic component (AC) of the Index of Orthodontic treatment need (IOTN) (Figure 1). Majority $(88 \%)$ of the subjects, irrespective of age and sex, perceived photograph number 1 followed by photograph number $2(8 \%)$ and photograph number $3(4 \%)$ as the best photograph of occlusion while photograph number 10 is perceived as the worst occlusion (76\%) followed by photograph number $9(11 \%)$, photograph number $7(5 \%)$, photograph number $6(4 \%)$, photograph number $8(3 \%)$ but mild difference in opinion was observed amongst age groups and sex for photograph number 4 .

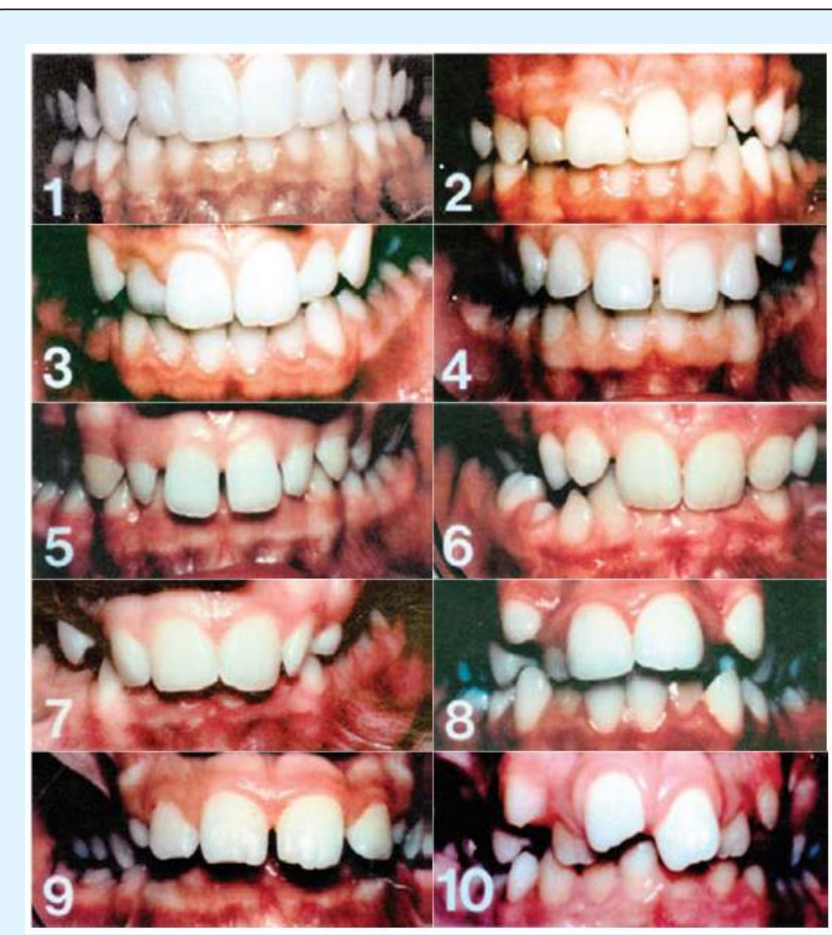

Figure 1: Standard IOTN Photographs. 
When the subjects were asked regarding the occlusion they would like to have amongst the 10 standard intraoral photographs, majority of the subjects choose photograph number 1 (83\%) followed by photograph number 3 (11\%), photograph number 2 (5\%) and photograph number $4(1 \%)$ while the occlusion they would never like to have was that of photograph number 10 (58\%), photograph number 8 (19\%), photograph number $9(14 \%)$, followed by photograph number $2,4,5$ and $7(1 \%)$.

When examined clinically, most of the subjects (74.3\%) had a dental appearance that required some form of orthodontic treatment either elective/desirable/mandatory according to DAI (Graph 2). For the purpose of statistical analysis, the category of desirable treatment and mandatory treatment was combined. Table 2 shows the correlation between the DAI and the subjective perception with treatment need. Kappa statistics revealed negative correlations amongst the subjective perception of the subjects and their actual treatment need assessed by DAI. Even though the correlations were negative, they were not statistically significant.

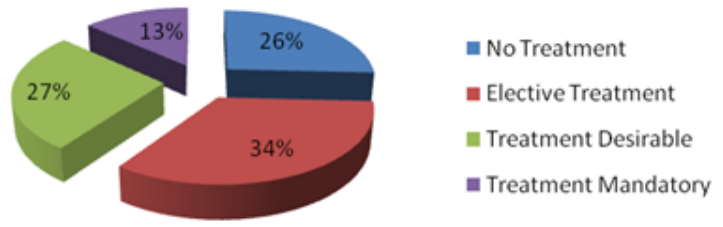

Graph 2: Treatment Needs of the subjects according to Dental Aesthetic Index.

\begin{tabular}{|c|c|c|c|c|c|}
\hline \multirow[b]{2}{*}{ Questions } & \multirow[b]{2}{*}{ Responses } & \multicolumn{3}{|c|}{ Dai Interpretation } & \multirow{2}{*}{$\begin{array}{c}\text { Kappa Value } \\
\text { (P-Value) }\end{array}$} \\
\hline & & No Treatment Need (\%) & Elective Treatment (\%) & $\begin{array}{l}\text { Treatment Desirable/ } \\
\text { Mandatory (\%) }\end{array}$ & \\
\hline \multirow{3}{*}{ Q1 } & Yes & 65.4 & 77.1 & 67.5 & \multirow{3}{*}{$\begin{array}{c}-0.038 \\
(0.516)\end{array}$} \\
\hline & No & 0 & 8.6 & 15 & \\
\hline & Do not know & 34.6 & 14.3 & 17.5 & \\
\hline \multirow{3}{*}{ Q2 } & Yes & 65.4 & 80 & 57.5 & \multirow{3}{*}{$-0.054(0.38)$} \\
\hline & No & 11.5 & 5.7 & 25 & \\
\hline & Do not know & 23.1 & 14.3 & 17.5 & \\
\hline \multirow{3}{*}{ Q3 } & Yes & 76.9 & 77.1 & 60 & \multirow{3}{*}{$\begin{array}{l}-0.015 \\
(0.793)\end{array}$} \\
\hline & No & 7.7 & 17.1 & 35 & \\
\hline & Do not know & 15.4 & 5.7 & 5 & \\
\hline \multirow{3}{*}{ Q4 } & Yes & 7.7 & 17.1 & 45 & \multirow{3}{*}{$\begin{array}{l}-0.103 \\
(0.074)\end{array}$} \\
\hline & No & 92.3 & 65.7 & 52.5 & \\
\hline & Do not know & 0 & 17.1 & 2.5 & \\
\hline \multirow{3}{*}{ Q5 } & Yes & 57.7 & 74.3 & 35 & \multirow{3}{*}{$0.049(0.495)$} \\
\hline & No & 7.7 & 11.4 & 25 & \\
\hline & Do not know & 34.6 & 14.3 & 40 & \\
\hline \multirow{3}{*}{ Q6 } & Yes & 80.8 & 80 & 80 & \multirow{3}{*}{$\begin{array}{l}-0.030 \\
(0.543)\end{array}$} \\
\hline & No & 11.5 & 8.6 & 15 & \\
\hline & Do not know & 7.7 & 11.4 & 5 & \\
\hline \multirow{3}{*}{ Q7 } & Yes & 26.9 & 42.9 & 70 & -0.039 \\
\hline & No & 69.2 & 54.3 & 25 & -0.542 \\
\hline & Do not know & 3.8 & 2.9 & 5 & \\
\hline
\end{tabular}

Table 2: Correlation between subjective perception \& treatment need of the subjects.

\section{Discussion}

There was a negative although insignificant correlation between the professional needs and the felt needs of the subjects belonging to low socio-economic status. A statistically significant difference was also observed amongst the subjective perception of boys and girls regarding their occlusion.

The study group of 12 to 15 years was taken as adolescence is said to be the age when an increase in awareness and facial aesthetics takes priority and children have a tendency to compare themselves with 


\section{Open Access Journal of Dental Sciences}

peers, models etc., $[4,6,7]$. This can be a major factor to demand for orthodontic services in a community. Also, it is known that the parent or the patient's concerns of orthodontic treatment need, do not always agree with professional evaluations of the same $[1,4,7]$. Hence, a validated self-administered questionnaire was used to know the perceived needs of the children regarding their occlusion. Intra-oral standard photographs, an aesthetic component of Index of Orthodontic Treatment Need was also included to judge the dental attractiveness of the subjects in better terms as it is considered to be a valid representation of dental attractiveness. Furthermore, visual stimuli might be more useful than verbal descriptions in assessing the aesthetic perception amongst children $[1,8]$. Low socio-economic status was specifically chosen to analyse the level of awareness, demand and felt need of the children belonging to this strata and the paucity of literature pertaining to this underprivileged group. Kuppuswamy's socioeconomic scale was taken as it more elaborative, more precise, takes into account education, occupation and family income to calculate the socio-economic status. To overcome the limitation of income being affected by inflation and consequent fall in the level in rupee, a conversion factor was calculated for 2012 and subsequently the family income scale for 2012 was obtained. Although authors tried to overcome the expected limitations of the questionnaire survey by employing the visual assessment in addition to the questionnaire but still the results obtained might have been influenced by their demand characteristics and may have influenced the results.

The study employed Dental Aesthetic Index (DAI) to assess the professional need of the subjects for orthodontic treatment as it an international index, identifies occlusal traits \& mathematically derives a single score. The reliability and validity of DAI has been well documented in various studies. It has been accepted by the WHO as a cross-cultural index [4].

The DAI has been compared with other treatment need indices in various studies $[3,4,9-14,15]$. It has been used in an epidemiological assessment of malocclusion and in evaluation of outcomes of orthodontic treatment. The results showed the out of the total 1010 subjects examined; almost $1 / 3^{\text {rd }}(70 \%)$ of the study population required some degree of orthodontic treatment. This finding is in consistent with study by Marques, et al. while it is in contrast to other studies $[9,16]$.

The present study revealed that a negative association between DAI and the self-perception with smile but was not significant. This finding is in contrast to the results of
Nayak, et al. (positive and insignificant). Thus, in the present study population, satisfaction with smile cannot be taken as an indicator of need for orthodontic treatment.

The correlation between DAI and self-satisfaction with dental appearance also turned out to be negative and insignificant. This was in agreement with the study by Yeh, et al. yet in contrast to other studies [4,17]. The positive correlation was obtained between DAI and subject's selfassessment of relative appearance of teeth as compared to their friends, corroborates with correlation found previously [4].

Analysis also revealed a weak, negative and insignificant relationship between DAI and the demand/ desire for orthodontic treatment. This finding is in contrast to study by Nayak, et al. (weak, positive and significant). The possible reasons for obtaining negative correlation between the two could be the lack of awareness about their occlusion; have never received any orthodontic advice or have never been to a dentist.

The study suggested that greater number of boys perceived themselves as having less attractive dentitions than girls which was statistically significant despite any objective evidence to support this point of view. Consequently, greater number of boys thinks that their teeth need orthodontic correction. Thus, the desire for treatment has been noted to be corresponding dissatisfaction with appearance. This finding is also in contrast to other studies where there no gender difference was reported $[1,3,11,18]$.

Thus, the results of the present study showed that the children belonging to low socio-economic status level of awareness of their malocclusions did not agree with their objectively determined orthodontic treatment need. The DAI and the satisfaction with dental appearance were found to be different from each other. This finding is in agreement with studies performed in other communities $[5,17]$ but in contrast to those found by Yeh, et al. Hence, the children belonging to low socio-economic status were less critical about their occlusion when compared with actual treatment needs.

\section{Conclusion}

Majority of the children were suffering from a severe and handicapping occlusion which requires a definitive / mandatory treatment. But the dearth of awareness and the funds to be applied in public health policies, particularly oral health, makes it necessary to restrict the available treatment to the most serious cases. As a result, at least priority based treatment must be afforded to 


\section{Open Access Journal of Dental Sciences}

persons with malocclusion which deems to be incapacitating, bearing in mind that India's current social, political and economic situation.

\section{References}

1. Mugonzibwa EA, Kuijpers Jagtman AE, Van't Hof MA, Kikwilu EN (2004) Perceptions of dental attractiveness \& orthodontic treatment need among Tanzanian children. Am J Orthod Dentofacial Orthop 125(4): 426-434.

2. Dogan AA, Sari E, Usken E, Saglam AM (2010) Comparison of orthodontic treatment need by professionals \& parents with different sociodemographic characteristics. Eur J Orthod 32(6): 672676.

3. Hamaci N, Basaran G, Uysal E (2009) Dental aesthetic index scores \& perception of personal dental appearance among Turkish university students. Eur J Orthod 31(2): 168-173.

4. Nayak UA, Winnier J, Rupesh S (2009) The relationship of Dental Aesthetic Index with Dental Appearance, Smile \& Desire for Orthodontic correction. Int J Clin Paediatr Dent 2(2): 6-12.

5. Hamdan AM (2004) The relationship between patient, parent \& clinician perceived need \& normative orthodontic treatment need. Eur J Orthod 26(3): 265-271.

6. Esa R, Razak IA, Allister JH (2001) Epidemiology of malocclusion \& orthodontic treatment need of 12-13 year-old Malaysian schoolchildren. Community Dental Health 18(1): 31-36.

7. Alhaija ES, Al Nimri K, Al Khateeb SN (2004) Orthodontic treatment need \& demand in 12-14 yearold north Jordanian school children. Eur J Orthod 26(3): 261-263.

8. Fox NA, Gilgrass T (2002) A comparison of the Index of Complexity Outcome \& Need (ICON) with the Peer Assessment Rating (PAR) \& the Index of Orthodontic Treatment Need (IOTN). Br Dent J 192(4): 225-230.

9. Marques CR, Couto GBL, Cardoso SO (2007) Assessment of orthodontic treatment needs in Brazilian schoolchildren according to the Dental
Aesthetic Index (DAI). Community Dent Health 24(3): 145-148.

10. Onyeaso CO (2008) Relationship between Index of Complexity, Outcome \& Need \& Dental Aesthetic Index in the assessment of Orthodontic treatment complexity \& need of Nigerian adolescents. Pesquisa Brasileria Odontopediatria e Clinica Integrada 8(2): 141-145.

11. Onyeaso CO (2003) An assessment of relationship between self-esteem, orthodontic concern, and Dental Aesthetic Index (DAI) scores among secondary school students in Ibadan, Nigeria. Int Dent J 53(2): 79-84.

12. Onyeaso OD, Ogunyinka A, Dosumu O, Cons NC, Jenny J (1999) Malocclusion and orthodontic treatment need of secondary school students in Nigeria according to the dental aesthetic index (DAI). International Dental Journal 49(4): 203-210.

13. Baca-Garcia A, Bravo $M$, Baca $P$, Baca $M$, Junco $P$ (2004) Malocclusions and orthodontic treatment needs in a group of Spanish adolescents using the Dental Aesthetic Index. Int Dent J 54(3): 138-142.

14. Ansai T, Miyazaki H, Yamashita Y, Takehara T, Jenny J (1993) Prevalence of malocclusion of high school students of Japan according to the Dental aesthetic index. Community Dent Oral Epidemiol 21(5): 301305 .

15. Onyeaso CO, Aderinokun GA (2003) The relationship between dental aesthetic index (DAI) and perceptions of aesthetics, function and speech amongst secondary school children in Ibadan, Nigeria. Int J Paediatr Dent 13(5): 336-341.

16. Burden DJ, Mitropoulos CM, Shaw WC (1994) Residual orthodontic treatment need in a sample of 15-16 year-olds. Br Dent J 176(6): 220-224.

17. Yeh M, Koochek A, Vlaskalic V, Boyd R, Richmond S (2000) The relationship of 2 professional \& occlusal indices with patients' perceptions of aesthetics, function, speech \& orthodontic treatment need. Am J Orthod Dent Orthop 118(4): 421-428.

18. Onyeaso CO, Sanu OO (2005) Perception of personal dental appearance in Nigerian adolescents. Am J Orthod Dentofacial Orthop 127(6): 700-706. 